\title{
Bystander Reactions to a Violent Theft: Crime in Jerusalem
}

\author{
Shalom H. Schwartz and Avi Gottlieb \\ Department of Sociology, University of Wisconsin-Madison
}

\begin{abstract}
Seventy-two male Israeli students were exposed to a violent crime in the course of a bogus discussion. Their awareness of other bystanders' lack of reaction to the emergency (social influence) and others' awareness of their actions (evaluation apprehension) were crossed in a $2 \times 2$ factorial design. An "alone" condition in which the subject was the only bystander controlled for the effects of others' mere presence (diffusion of responsibility). Helping was reduced by diffusion of responsibility and slowed by negative social influence but was increased by evaluation apprehension. Differences traceable to social influence appeared prior to those from the other processes. Implications of these findings for the measurement of helping and the interpretation of bystander decision making are discussed.
\end{abstract}

The widely decried unresponsiveness of 38 witnesses during the violent murder of Kitty Genovese (Rosenthal, 1964) was the major stimulus to social-psychological research on bystander behavior in emergencies. Yet none of this research has confronted subjects with an emergency caused by a violent crime. The victims' need has commonly been generated by impersonally caused accidents (e.g., falling bookcases, Latané \& Rodin, 1969), physical illness (e.g., nervous seizures, Darley \& Latané, 1968), or nonviolent crimes (e.g., theft, Moriarty, 1975). Bystanders have been exposed to some violence, but only in the form of fighting between children (Latané \& Darley, 1970) and between participants in a psychodrama (Borofsky, Stollak, \& Messé, 1971).

Bystander responses to impersonal and nonviolent emergencies are important, of course, but they may differ from responses to violent crime. Intervention in violent crime is likely to be viewed as more dangerous, especially when the attacker is still present, when extended and unpredictable involvement with

The research reported here was supported by National Science Foundation Grant SOC 72-05417 to the first author.

We would like to thank Bernard Goitein who served as experimenter. We are also indebted to John Fleishman, Bibb Latané, and Amos Tversky for their comments on earlier drafts.

Requests for reprints should be sent to Shalom Schwartz, Department of Sociology, University of Wisconsin, Madison, Wisconsin 53706. authorities (e.g., police, courts) is possible, when fear of becoming the next victim may induce particularly strong emotional stress, and when violence-precipitated need may be perceived as especially vivid or immediate. The current study sought to determine whether processes postulated to explain bystander intervention in past studies apply in a case of violent crime.

Latané and Darley (1970) have proposed three analytically distinct processes that may account for the oft-observed tendency of bystanders to inhibit each others' responsiveness in emergencies: social influence, audience inhibition, and diffusion of responsibility. Characteristics of these processes are discussed below. We contend that many of the studies interpreted as demonstrating the effects of one or another process have confounded two of the processes or even all three. A second aim of the present research is to isolate the effects of all three intervening processes in a single study by systematically varying conditions conducive to each.

The process of social influence requires that the focal bystander be aware of the reactions of other bystanders. The reactions of others provide informational cues about the seriousness and reality of the emergency and normative cues about appropriateness of responses. Latané and Darley (1970) have emphasized inhibition of response through visual observation of the inaction of others. Logically, however, communication of others' responses through nonvisual channels should 
also suffice as a source of social influence; and social influence may promote intervention as well as inhibit it, depending on the nature of the responses perceived (e.g., Bickman, 1972).

The process that Latané and Darley (1970) labeled audience inhibition requires that focal bystanders believe others are aware of their responses. It refers to the bystanders' concern over others' expectations and evaluations of their behavior and the desire to optimize these evaluations. This process might preferably be called evaluation apprehension to avoid any directional connotation. This apprehension may either foster or inhibit intervention depending on what expectations the bystander believes others hold.

Diffusion of responsibility requires only that a bystander think others who might respond to the emergency are also present. Feelings of responsibility can then be diluted because it may be less necessary for any one person to act; and any anticipated blame for nonresponse may also be reduced because it would be shared by others. Increases in the number of bystanders to an emergency, especially competent bystanders, have been interpreted as conducive to diffusion of responsibility (e.g., Darley \& Latané, 1968; Schwartz \& Clausen, 1970). If the additional bystanders are unable to respond (e.g., Bickman, 1971 ), or if responsibility is explicitly assigned to the focal bystander (Tilker, 1970), however, the diffusion process is unlikely.

From the above discussion is becomes clear that a pure diffusion-of-responsibility effect can only be isolated when the bystander believes that others are present and that neither she/he nor they are aware of each others' responses. This implies that firm conclusions about diffusion of responsibility cannot be drawn from most of the laboratory and field studies in which the number of bystanders has been varied because bystanders have been aware of one another to some degree (e.g., Clark \& Word, 1972; Latané \& Darley, 1968; Latané \& Dabbs, 1975; Latané \& Rodin, 1969; Piliavin, Rodin, \& Piliavin, 1969; Smith, Smythe, \& Lien, 1972).

Even the now classic study explicitly intended to manipulate only conditions conducive to diffusion of responsibility (Darley \&
Latané, 1968) was not designed to control fully against the occurrence of social influence and evaluation apprehension. Bystanders to the victim's nervous seizure had an additional 4 minutes to respond after an automatic circuit switcher began the next participant's turn. Since the order of turns was varied (Darley \& Latané, 1968, p. 379, Footnote 2), the subject may have expected either to hear another bystander (social influence) or to be heard herself by the others (evaluation apprehension) during this period, depending upon whose turn followed the victim's. In the replication of this study by Schwartz and Clausen (1970), the naive subject's turn always followed the victim's, a situation conducive to evaluation apprehension.

In both of these studies, there was evidence for pure diffusion, however, since lone female bystanders responded significantly more frequently than those who believed four others were present even before the circuit switched. In the replication with males by Horowitz (1971), other subjects were always scheduled to be heard next, a situation conducive to social influence; and no pure diffusion effect was isolated.

The final emergency study that meets the awareness requirements for isolating diffusion of responsibility with an increase in the number of bystanders was done by Bickman (1971). In this study female bystanders responded more slowly to the victim of a fallen bookcase when in the presence of another able bystander than when alone, although the proportions responding did not differ. In sum, unequivocal evidence for the diffusion of responsibility process is sparse, and it pertains exclusively to female bystanders.

Pure social influence and evaluation apprehension effects also do not abound in the bystander literature. In most of the studies purportedly demonstrating social influence, bystanders witnessed the emergency in each other's presence. Hence, they may also have been affected by concern regarding others' expectations and evaluations (e.g., Clark \& Word, 1972; Latané \& Dabbs, 1975; Latané \& Darley, 1968; Latané \& Rodin, 1969; Ross \& Braband, 1973; Smith, Vanderbilt, \& Callen, 1973). Another of Bickman's studies (Bickman, 1972), again with female subjects, 
may provide the only evidence for a pure social influence effect. Bystanders who heard a scream and crash responded significantly more quickly when they thought another bystander from whom they were separated communicated that she thought there was a definite emergency. The study was structured so that the other bystander could not be aware of the subject's responses. To the extent that this was correctly perceived, evaluation apprehension should have been minimized.

Little work has been done on isolating evaluation apprehension effects. Beaman, Fraser, Diener, Kelem, and Westford (Note 1) manipulated an appropriate variablewhether the focal bystander could be seen by another bystander. Unfortunately, however, this manipulation was only partially crossed with whether the focal bystander could observe another bystander's unresponsiveness. The absence of a condition in which the focal bystander neither observed nor was observed by the other prevents any clear interpretation of their findings.

Although audiences may inhibit helping because self-consciousness leads people to delay action until they are sure of themselves, as Latané and Darley (1976) suggested, the following reasoning leads us to expect that evaluation apprehension will promote helping in many circumstances: Data from Heberlein (Note 2) indicate that the vast majority of people feel some obligation to help others who are in trouble. This is supported by the very high rate of helping by lone bystanders in emergency studies. People tend to believe that other witnesses to emergencies share their sense of obligation, as corroborated by Bickman's (1971) finding that 14 of 15 subjects expected another able bystander to help. Assuming that bystanders project their own expectations to others, they are likely to view intervention as the response socially expected of them, so that evaluation apprehension should promote helping.

Three hypotheses about bystander intervention may be derived from the preceding discussion, each reflecting a different intervening process. First, mutually unaware bystanders to an emergency help less than lone bystanders (diffusion of responsibility). Second, bystanders help less when they are aware that another bystander is unresponsive than when they are unaware of the other bystander's reactions (social influence-negative). Third, bystanders help more when other bystanders present are aware of their reactions than when their reactions are unknown to the other bystanders (evaluation apprehensionpositive).

The third hypothesis may be complicated by mutual awareness conditions in which both social influence and evaluation apprehension are likely because the others' failure to respond might suggest negative expectations. The one interpretable comparison in Beaman et al. (Note 1) indicates significantly less help with exposure to the combination of evaluation apprehension and negative social influence than with exposure to the latter alone. Whether evaluation apprehension promotes helping under mutual awareness, or whether it interacts with negative social influence to further depress helping, may depend upon which process takes hold first in a particular emergency. Because conditions conducive to all three processes are manipulated in this study, we can examine possible differences in the timing of their impacts on behavior.

In a short report that recently came to our attention, Latané and Darley (1976, pp. 1820) describe an experiment to which our own was conceptually similar in that we both tried to isolate the three bystander processes by manipulating channels of communication. Their analysis did not treat the three processes independently, however, thus revealing significant inhibiting effects only for combinations of two or more processes. Our reanalysis indicates that all three independent effects were small and insignificant. Possible reasons for the small size of effects in their study may include the limited variability of response (common for serious, unambiguous emergencies; cf. Clark \& Word, 1972, 1974), the use of a single additional bystander (also insufficient to produce a reliable impact in Darley \& Latané, 1968), and the use of mostly male subjects.

Two other points require mention regarding the current study. Schwartz and Clausen (1970) found that the number and ability of other bystanders influenced helping, presumably through diffusion of responsibility, only 
among subjects who scored below the median on a scale that measures the tendency to deny responsibility. ${ }^{1}$ This scale was included here in an attempt to replicate this effect. Finally, because this study was performed in Israel, it can provide some data on the crosscultural validity of inferences regarding bystander processes.

\section{METHOD}

\section{Subjects and Design}

Male undergraduates at the Hebrew University, Jerusalem, were recruited to participate in a discussion for "developing a high school sex education curriculum." Subjects were paid the equivalent of $\$ 3$ for $1 \frac{1}{2}$ hours. The subject's awareness of other bystanders' reactions to attack (aware-unaware) and other bystanders' awareness of the subject's reaction (aware-unaware) were crossed in a $2 \times 2$ design. Subject's awareness varied the likelihood of social influence, and others' awareness varied the likelihood of evaluation apprehension. An alone condition in which the subject was the only bystander was used to isolate the effects of diffusion of responsibility. After stratification at the median on responsibility denial scores, 72 subjects were randomly assigned to one of the five experimental conditions.

\section{Procedure}

The experiment was conducted at night in an isolated campus building whose doors were locked to cnhance plausibility. The subject was led down a corridor past rooms labeled to suggest there would be six participants (two in the alone condition), was told that the person in Room 1 had already arrived, and was placed in Room 2. He was given a responsibility denial questionnaire and a set of health questions purportedly important for assessing his views on sex education. The latter was intended to screen out people with serious physical or emotional problems; however, none were identified.

During questionnaire completion the research assistant interrupted the subject to show him a tape recorder found in the hall and ask if it belonged to him. When he picked up the completed questionnaires, the assistant mentioned that the recorder belonged to the person in Room 1 (the future victim). Thus subjects learned that the object of the later theft belonged to the victim.

Subjects next donned earphones to receive a prerecorded explanation of the general procedures for the discussion and the rationale for physical separation of the discussants (to reduce inhibitions and stimulate discussion of a potentially embarrassing topic). They then filled out questionnaires on their own sex education and pressed a signal button that rang a bell when they were done. This signaling gave practice in one potential mode of reporting. Before proceeding the assistant checked the intercom and signal system and administered the manipulation of others' awareness in the appropriate conditions, as explained below.

The prerecorded instructions resumed with a detailed explanation of procedures that subjects also followed on a written outline. First, each participant in turn was to discuss a topic chosen from a list provided for 2 minutes, starting with the person in Room 1 (the victim), then the subject, and so on. Following a break the discussion would continue in the same order, with each person talking for $2 \frac{1}{2}$ minutes on a new topic. In this second phase each talk would be followed by $2 \frac{1}{2}$ minutes for everyone either to join in a free exchange of remarks about the immediately preceding speaker's views (subject aware of others) or to jot down remarks (subject unaware). A third phase of open discussion among participants would follow. Subjects were assured that no one else would be listening to their discussion. To this end the intercom system would switch automatically, and the researcher would receive the participants' recommendations only in written form at the end of the discussion.

Mutual awareness of reactions was manipulated by the descriptions of how the intercom system worked, which were given in the recorded instructions and in the remarks made by the assistant. Awareness referred to the ability to hear any physical movement (e.g., scraping of a chair), calling out, or ringing of a bell from rooms in which the microphone was on.

Subject's awareness. Subject's awareness of other bystanders' reactions determined whether or not social influence might be operative. In the aware condition, all mikes were to be on throughout the three phases. Everyone was cautioned to remain quiet during other persons' turns to avoid noise interference. Thus any sounds of helping actions by others would presumably be heard by the subject. Since the fictitious bystanders made no sounds throughout the emergency, subjects were exposed to social influence opposed to intervention.

In the not aware condition, only the mike of the person whose turn it was to talk would be on during the first two phases. During the $2 \frac{1}{2}$-minute period following each turn in the second phase, all mikes would shut off. The victim's mike would remain on, however, since, as the assistant explained, Room 1 had special equipment also being used for other research. Thus, during and after the attack, only the victim could be heard, and the subject could not know how others were reacting. $\mathrm{He}$ was therefore not exposed to social influence.

Others' awareness. The subject's perception of whether other bystanders were aware of his reactions determined whether he was likely to experience evaluation apprehension.

In the aware condition, when all mikes were on,

1 Previously called ascription of responsibility, this scale is now labeled responsibility denial (Schwartz, in press). 
other bystanders could, of course, be aware of the subject's reaction. When only the speaker's mike was scheduled to be on, others were made aware as follows: During the intercom check the assistant discovered that the subject's mike did not shut off automatically. $\mathrm{He}$ asked the subject to write a note describing this problem for a technician-thereby reinforcing perception of the others' awareness condition. The assistant then concluded that the discussion could go on as long as the subject was not noisy. The subject therefore believed that he himself could be heard by others throughout the emergency.

In the not aware condition, when only the speaker's mike was on, other bystanders could, of course, not be aware of the subject's reactions. In the "subject aware" condition, however, when all mikes were scheduled to be on, others' awareness was blocked as follows: During the intercom check the assistant discovered that no one could hear the subject except Participant 1, unless all the other mikes were off. The assistant therefore arranged the automatic system to shut off the other mikes during the subject's turn, enabling the subject to participate in all but the free exchanges. The assistant asked the subject to leave a note describing this problem for the technician. Thus, during and after the attack, the subject believed that he himself could not be heard by other bystanders, since all the other mikes were on.

Alone. Only the subject and the future victim participated in this condition, and both mikes were on all the time. Diffusion of responsibility to other bystanders was therefore not possible, in contrast to the preceding conditions.

After answering questions about procedures, the assistant announced that he was starting the automatic switching device and that he was going down the hall to the research director's office where he could be contacted, if necessary, by pressing the signal button. The assistant then started a tape with prerecorded voices for the various participants and a silent period during the subject's turn. The discussion proceeded through the first phase, the break, and $43 \mathrm{sec}$ into the future victim's talk beginning the second phase. At this point, the victim interrupted his talk to answer a knock at his door. Subjects overheard a conversation between the victim and a male stranger that quickly escalated into a fight. The intruder apparently grabbed the victim's tape recorder, and the victim tried to stop him. Arguing, blows, and the crash of a person falling were heard, followed by the slamming of a door. The intruder had apparently escaped with the victim's recorder, leaving him moaning on the floor. The moaning, interspersed with barely audible remarks, continued intermittently for another $2 \frac{1}{2} \mathrm{~min}$.

The assistant recorded the subject's response latency for ringing the bell, calling out, and/or leaving the room, waiting 1 additional minute before appearing. He then asked the subject what had happened and what he was doing. Subjects who failed to respond within 5 minutes were contacted in their own room. After ostensibly checking that the victim was okay, the assistant gradually debriefed the subject. Finally, subjects completed two written questionnaires, one to check manipulations and perceptions and the other-not to be seen by the assistant-anonymously soliciting the subjects' evaluation of the ethics of the study on behalf of a psychology department committee.

\section{RESULTS}

Sixty-five percent of the bystanders responded to the emergency: $22 \%$ attempted a direct helping response by trying to enter the victim's room; $14 \%$ emerged from their room and sought to alert the researchers; $29 \%$ rang their bell to alert the researchers. None tried to approach another bystander's room. Among those who responded, type of response was unrelated to experimental treatment. The quickest response was only $12 \mathrm{sec}$ after the intruder's entry into the room, and the slowest was $195 \mathrm{sec}$. Those who failed to respond were assigned an arbitrary $255-\mathrm{sec}$ latency, equivalent to the time at which the experimenter entered their room and a full minute later than the slowest response.

\section{Perceptions of the Situation and the Manipulations}

Perceptions of the communications system and of the experimental arrangements were checked both in the verbal debriefing and in the written questionnaire. Four persons were excluded from the sample prior to analysis because they thought that the tape recorder belonged to the intruder. This misunderstanding implied that they, unlike other subjects, witnessed a provoked crime. All of the manipulations of awareness were correctly perceived by $70 \%$ of the participants, and an additional $19 \%$ made only partial, minor errors (e.g., could hear others' verbal responses but not their ringing of the bell). Misperceptions of awareness were not related to experimental treatment. One person incorrectly thought that other bystanders were present. All misperceivers were retained in the analysis as a conservative measure.

As might be expected when persons are exposed to a threatening emergency, many reported some suspicion. These reports unquestionably reflect both real doubts and defensive justifications of inaction or inde- 


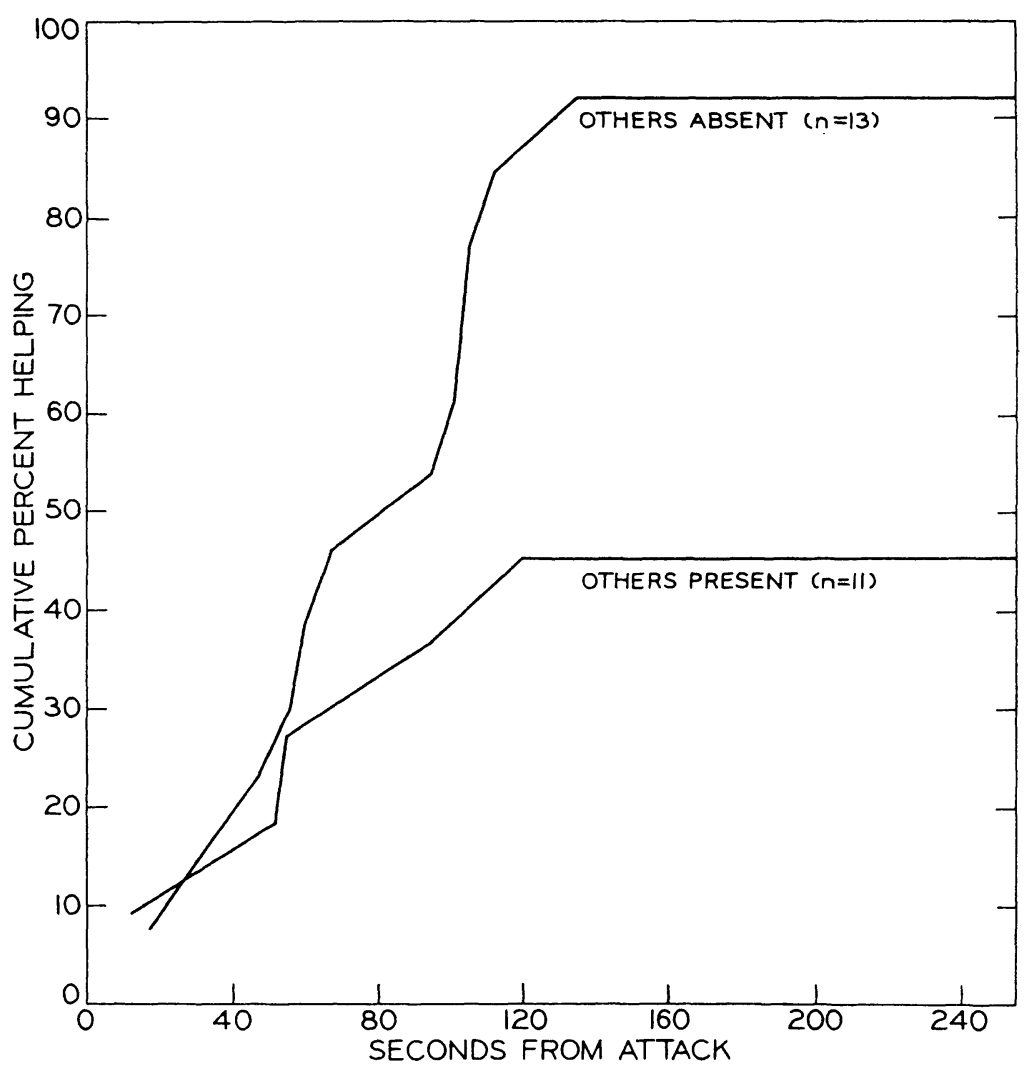

FIGURE 1. Cumulative proportion of subjects responding over time: Diffusion of responsibility.

cision. Only five persons who immediately and spontaneously told the experimenter that they disbelieved the attack and who betrayed no hint of belief were excluded from the analysis, one from each experimental condition. Self-reported suspicion, measured on a 100 point scale, was related to helping for the total sample, but controlling for suspicion did not influence the effect of the manipulated variables, because suspicion was unrelated to experimental treatment.

\section{Effects of Independent Variables}

Dichotomized responsibility denial did not interact with any of the manipulated variables in their effects on helping, nor did responsibility denial scores correlate significantly with any index of helping. Responsibility denial is therefore not considered further in the analyses reported below.

Diffusion of responsibility. To test for this theorized process, responses of lone bystanders were compared with those of bystanders who were in the presence of mutually unaware others. Diffusion of responsibility showed a substantial effect: Ninety-two percent of those who were alone intervened versus $45 \%$ of those in the mutually unaware condition $\left(\chi^{2}=4.27, p<.05\right)$. Figure 1 shows the cumulative proportion helping in each condition as a function of time following the attack. These curves indicate that diffusion of responsibility had virtually no impact on behavior during the first $55 \mathrm{sec}$ and only began to influence responses thereafter.

To assess the timing of effects reflected in the curves, the following analysis was performed: The lone bystander sample and the mutually unaware sample were each dichotomized at their respective median response times. A Mann-Whitney test, used to compare the distribution of responses in the two premedian subsamples, revealed no difference, indicating no effects of diffusion of respon- 


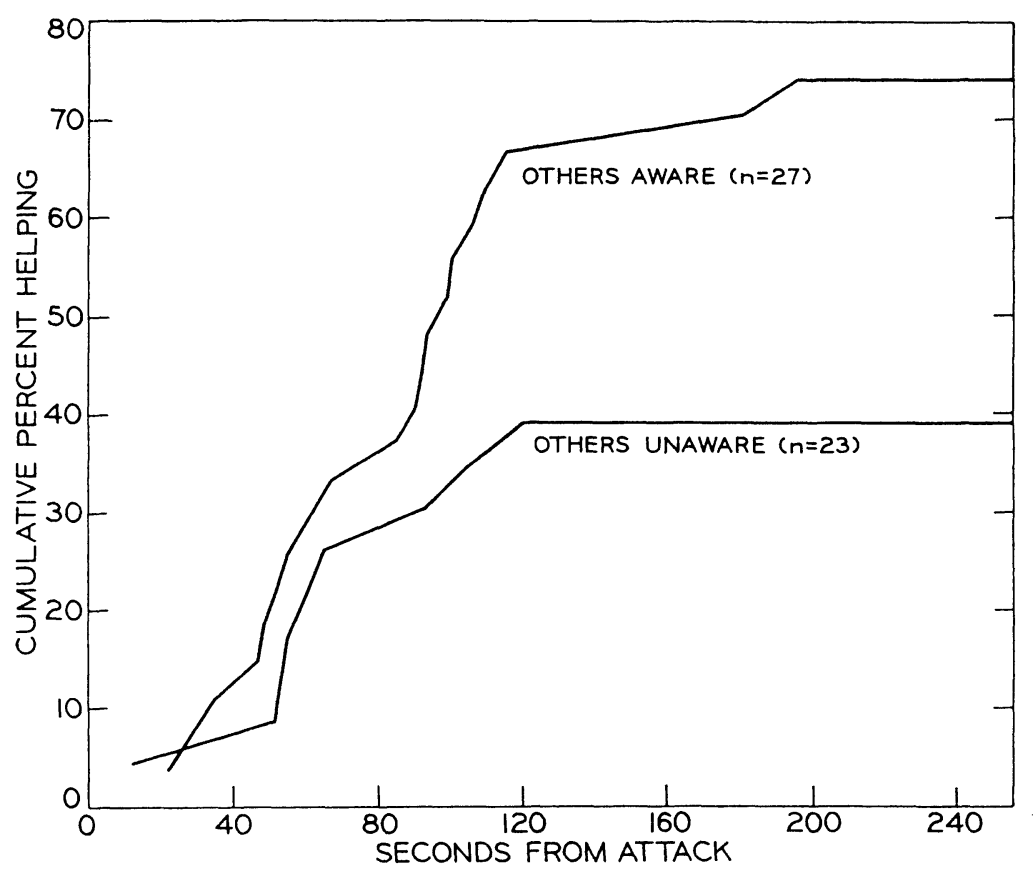

FIGURE 2. Cumulative proportion of subjects responding over time: Evaluation apprehension.

sibility among early responders. A comparison of the two postmedian distributions indicated a significant effect due to diffusion of responsibility $(U=2.5, p<.02) ;{ }^{2}$ lone bystanders responded sooner.

Responses in the four conditions created by crossing the subject's awareness of other bystanders' reactions with others' awareness of the subject's reactions were analyzed to test for the remaining theorized processes. Since evaluation apprehension and social influence did not interact in their impact on helping $\left(\chi^{2}=.28, n s\right.$, for interaction; cf. Goodman, 1964), the two are treated independently.

Evaluation apprehension. Bystanders were significantly more likely to respond to the emergency when others could be aware of their reactions $(74 \%)$ than when others were unaware $\left(39 \%: \chi^{2}=4.87, p<.05\right)$, regardless of whether they themselves knew of the others' inaction. Responses plotted over time (Figure 2) reveal a pattern similar to that found for diffusion of responsibility: Differentiation between the two distributions did not begin to appear until sometime after the assault (approximately $90 \mathrm{sec}$ in this case). Statistical tests reinforced the inference suggested by the curves that evaluation appre- hension influenced late rather than early responding. Dichotomizing each sample at its median response time revealed no significant difference between the two conditions for distributions of those who responded before the median time. The distributions for the postmedian groups were, however, marginally different $(U=42, p<.10)$.

Social influence. Although bystanders who were exposed to negative social influence reacted less frequently $(48 \%)$ than those who were not aware of the others' reaction $(68 \%)$, this difference was not reliable $\left(\chi^{2}=1.31\right.$, $n s)$. The cumulative curves of responses for this process (Figure 3 ) reveal a reversal of the pattern for both diffusion of responsibility and evaluation apprehension. Before $55 \mathrm{sec}$ had elapsed, not one of those subjects exposed to negative social influence had helped, whereas $32 \%$ of the subjects who could not know of others' responses had already taken action. For the remainder of the time, the rates of response were approximately the same. Statistical tests on the dichotomized distributions showed a difference due to social influence for

\footnotetext{
${ }^{2}$ All significance levels in this article are two-tailed unless otherwise indicated.
} 
those who responded before the median time $(U=28, p<.02)$ but no difference for the postmedian groups. A Mann-Whitney test on the whole sample indicated that those subjects exposed to negative social influence responded more slowly $(z=2.02, p<.02$, one-tailed $)$. Thus social influence appears to have slowed intervention significantly even though it did not conclusively block it.

\section{Subjective Perceptions}

Following the debriefing participants completed a written questionnaire in which they were asked to describe their thoughts and feelings during the emergency, indicate whether they felt that various characteristics of the situation encouraged or inhibited their helping, and check a list of thoughts and feelings. Four ideas were mentioned by at least $25 \%$ of the participants in response to an open-ended question about their thoughts and feelings: doubts about authenticity $(48 \%)$, sense of obligation to help $(37 \%)$, "why don't others react?" $(37 \%)$, and thoughts about actions to take $(27 \%)$. Sense of obligation was mentioned significantly more $(p<.01)$ and doubts were mentioned significantly less $(p<.05)$ by those who helped than by those who did not. It must be noted that these responses, as well as those discussed below, may partly reflect retrospective justifications of behavior.

Diffusion of responsibility. Three quarters of those subjects in the conditions used to uncover this process thought that the presence or absence of other bystanders had no influence on their behavior. Those subjects in the alone condition were somewhat more likely to believe they had been influenced than those in the mutually unaware condition (38\% vs. $9 \%$ ). Of those who acknowledged influence, all but one subject believed that adding bystanders would inhibit helping. Spontaneous thoughts about their own sense of obligation were mentioned by $62 \%$ of those subjects who were alone versus $27 \%$ of those subjects who were mutually unaware. In response to the list of thoughts, $36 \%$ of the subjects in the mutually unaware condition but none in the alone condition checked thoughts about reduced responsibility.

Diffusion of responsibility was possible in all four conditions with multiple bystanders. Comparisons of subjective perceptions in the alone condition with the combined multiple bystander conditions revealed the same pattern of differences found with the mutually unaware condition; and the difference for thoughts about reduced responsibility was significant $(p<.01)$. Thus, although the

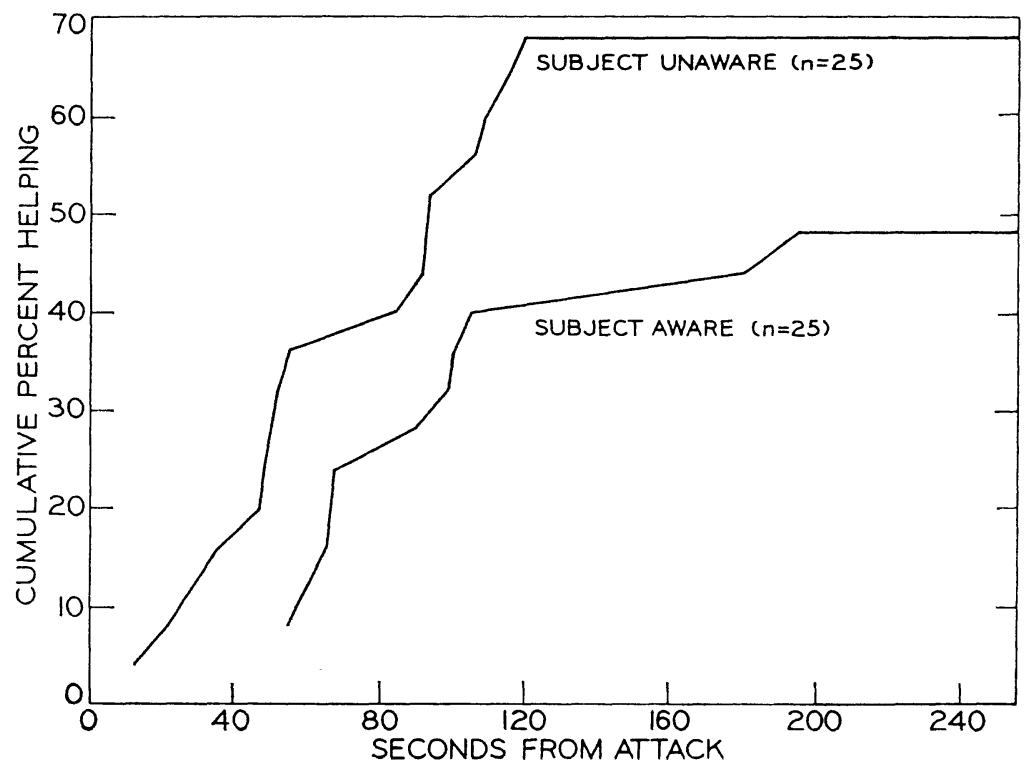

Figuke 3. Cumulative proportion of subjects responding over time: Social influence. 
TABLE 1

Analyses of Variance in Helping Using Response LATENCY aND SPEED SCORES

\begin{tabular}{llll}
\hline \hline \multicolumn{1}{c}{ Source } & & \multicolumn{2}{c}{$F$ values } \\
\cline { 3 - 4 } & $d f$ & $\begin{array}{c}\text { Response } \\
\text { latency }\end{array}$ & $\begin{array}{l}\text { Speed } \\
\text { score }\end{array}$ \\
\hline Diffusion of responsibility & 1,22 & $5.41^{*}$ & 1.60 \\
Evaluation apprehension & 1,46 & $4.28^{*}$ & 1.92 \\
Social influence & 1,46 & 3.40 & $4.66^{*}$ \\
\hline
\end{tabular}

$* p<.05$.

majority of participants denied any effect for adding bystanders, those subjects who recognized an effect thought that it promoted diffusion of responsibility. Furthermore, self-reported thoughts and feelings reflected the expected variations in sense of responsibility.

Evaluation apprehension. Fully $88 \%$ of the participants denied that others' awareness of their own reactions had any effect. The perceived effect of the mere presence of others was moderated, however, by whether or not these others could possibly be aware. Fiftynine percent in the aware versus $22 \%$ in the unaware conditions $(p<.01)$ said they were influenced by the presence of others, but this influence was perceived as inhibiting helping! Although the actual enhancement of their helping by others' awareness apparently went undetected by participants, self-reports indicate that others' awareness increased their thoughts about their own sense of obligation $(41 \%$ vs. $17 \%)$ and about others expecting them to help ( $22 \%$ vs. $4 \%$ ). Interestingly, those subjects whose reactions were unknown to others were significantly more likely to report thinking that the attack was ruining the discussion ( $39 \%$ vs. $11 \%, p<.05)$, suggesting that they felt more detached toward the emergency.

Social influence. There were some signs that the impact of negative social influence on behavior was recognized by the participants. Of those subjects able to know that others were inactive, $54 \%$ said they were inhibited by this knowledge. Among those who did not know what others were doing, $32 \%$ stated that their lack of knowledge inhibited them and $12 \%$ stated that it promoted helping. Moreover, knowing versus not knowing about others' inaction was significantly related to thinking spontaneously that others' reactions made helping inappropriate ( $64 \%$ vs. $28 \%$, $p<.05)$. Spontaneous thoughts about own obligation tended to be more frequent among those who did not know what others were doing $(44 \%$ vs. $16 \%, p<.10)$.

\section{Discussion \\ Measurement of Helping}

Previous bystander studies have reported helping responses in various ways, most commonly using proportion responding, response latency in seconds, and speed scores constructed by reciprocal transformations of response latencies. Justifications for choice of dependent variable have referred to meeting statistical assumptions and to minimizing the impact of the arbitrary time assigned to nonresponders. This choice also determines, however, how the distribution of responses over time will influence the outcomes of parametric analyses. The use of speed scores is likely to yield significant effects if a differentiation of responses occurs early, even if this differentiation remains constant or decreases thereafter. This is because speed scores give more weight to early as opposed to late variation in responses, and they deemphasize the difference between late response and nonresponse. Analyses of response latencies, on the other hand, are more likely to yield significant results when a differentiation among those who respond to the emergency occurs gradually or when the difference is primarily due to the relative proportions responding, since those who fail to respond are typically given an arbitrary, long response latency.

The use of parametric tests with latency and speed-score data from the current study illustrates these patterns (Table 1). Both diffusion of responsibility and evaluation apprehension, whose effects emerged relatively late and led to differences in proportion helping, yielded significant effects only with latency as the index of helping.

By contrast, the effect of social influence, which emerged early but did not lead to differences in proportion helping, was significant only for speed scores. Given that the metric chosen influences conclusions from parametric tests, and in the absence of a metric with clear 
psychological meaning, nonparametric tests may be most reasonable both practically and intuitively at this time. Although proportions responding are clearly meaningful, finding differences in effects over time requires tests that consider order of response, such as the Mann-Whitney. It is also desirable to provide response curves that can clarify the nature of these effects.

\section{Inferences and Interpretations}

This study has demonstrated that all three processes by which bystanders to emergencies presumably influence each others' responses do indeed have independent, unconfounded effects on helping. The findings for diffusion of responsibility and social influence also extend the generalizability of effects beyond past research because these processes were observed (a) among male bystanders; (b) in response to a violence-precipitated, personally threatening emergency; and (c) in a crosscultural context.

The presence of diffusion of responsibility for males in this study contrasts with its absence in Schwartz and Clausen (1970). These authors noted that some of their additional bystanders were female, and they suggested "that the introduction of female bystanders may increase the incentive of males to intervene, counterbalancing the effects of diffusion of responsibility" (p. 308). Our findings confirm their expectation that "the addition of male bystanders alone [would reduce helping] by males" (p. 308).

Even though negative social influence significantly inhibited responses during the period shortly following the emergency, it did not reliably reduce the final proportion helping. The absence of a social influence effect on the proportion of subjects who ultimately helped may reflect the fact that some of the subjects in the condition in which they could not hear others' reactions were nonetheless exposed to a measure of negative social influence. According to self-reports, $44 \%$ of the subjects in this condition conjectured that no one else had helped. Thus these subjects may have been influenced negatively by the presumed behavior of others. Situations in which others' reactions are unknown are necessarily ambiguous with respect to social influence.
Among those who were able to hear others' reactions, $80 \%$ correctly reported that no one else helped. Yet a substantial proportion of those subjects in the negative social influence condition ultimately helped $(48 \%)$. The pressures contrary to intervention were apparently insufficient to deter these individuals, but their decision was probably more complicated and therefore slower because they had to arrive at an interpretation of events at variance with the information available to them before responding. We should note that this study provides no evidence on the effects of positive social influence.

The current study provides the only evidence for an independent impact of evaluation apprehension on helping. The differences in self-reported thoughts and feelings noted above draw attention to three possible mechanisms underlying this effect: (a) The absence of an audience produced a sense of detachment from events that lowered the emotional impact of the emergency and its power to activate norms. (b) The presence of an audience made the personal sense of obligation more salient, perhaps through heightening objective self-awareness (Duval \& Wicklund, 1972). (c) The presence of an audience added the force of perceived social expectations to that of self-expectations. The latter might occur even when others are believed not to be responding if they are perceived by the bystander as inactive because they are waiting upon his/her own response.

As indicated by the absence of an interaction between subject's awareness and others' awareness, evaluation apprehension enhanced helping regardless of social influence. This finding contrasts with the results of two earlier studies (Latané \& Darley, 197.6; Beaman et al., Note 1) in which the presence of an audience in combination with negative social influence reduced helping. Considering the mechanisms proposed here, perhaps subjects in the no-audience conditions in the earlier studies felt less detached because they were one of only two bystanders. Moreover, in the negative social influence condition in Latané and Darley (1976), the other bystander apparently returned to his work after noting the emergency and could be seen to show no interest in the subject. The confederate in 
Beaman et al. (Note 1) "retained a nonreactive demeanor." This apparent disinterest may have blocked or weakened the second and third mechanisms. Disinterest on the part of an inactive other might undermine perceiving the other as waiting for and holding positive expectations for the bystander to react. Further research is required to identify the conditions under which various mechanisms produce evaluation apprehension effects.

Although evaluation apprehension was undoubtedly low in the no-audience conditions of past studies, it was probably not entirely absent. In each case bystanders may have been concerned about the expectations of the victim and/or the experimenter who knew of their presence. Moreover, bystanders may have recognized that they could expose themselves to the evaluations of others by intervening. These sources of evaluation apprehension may be minimized by experimental design, but another source-anticipation of evaluations by those to whom bystanders may have to report their actions in the future-is present even in alone conditions.

Findings by Schwartz and Clausen (1970) that diffusion of responsibility effects were moderated by responsibility denial scores and that increasing the number of bystanders influenced the type of response (direct vs. indirect) were not replicated in the present study. Perhaps this is because both of these earlier effects were found with females but not males. Furthermore, the absence here of moderation by responsibility denial may be due to the use of a translated scale in a different cultural context; and the lack of effects on response type may be traceable to the substantial differences in the emergencies and the types of help called for. The high rate of indirect help may reflect the potentially high cost of intervention in this study (cf. Piliavin et al., 1969).

The cumulative response curves as well as the statistical analyses for the various conditions indicate that the impact of the three processes on intervention emerged in a particular sequential order. First came social influence; diffusion of responsibility and evaluation apprehension followed approximately together. Because earlier studies did not vary the conditions conducive to these processes orthogonally, additional data on comparative timing are unavailable. Further research is needed to validate or modify the pattern we have uncovered.

We have observed the timing of overt helping responses, but we do not know when the decisions leading to these responses were made. Assuming that the timing of intervention reflects the timing of decisions, however, our findings support the generally accepted view (cf. Latané \& Darley, 1970; Schwartz, 1970) that the first issue confronting a bystander is to decide upon the reality of need and appropriateness of help, a decision partly based upon the situational definition provided by others (social influence)., Following this comes a decision regarding one's own personal obligation, which may be reduced by the presence of others (diffusion of responsibility) and may be influenced by their perceived expectations (evaluation apprehension). The latter, we note, may enhance the sense of personal obligation.

\section{Ethics}

The ethical problems with deceit were complicated in this experiment by the risks of emotional shock from witnessing a violent attack and by self-deprecation for failure to help. In order to detect undesirahle impacts that might require halting the research, we supplemented the debriefing with an anonymous "ethics questionnaire" administered after payment was made. The following responses reflect the reactions of all 72 participants.

Current feelings were measured on a set of 90-mm self-descriptive scales. Mean responses for all seven negative feelings (upset, angry at experimenter and at self, depressed, embarrassed, nervous, guilty) fell below the segment marked "slightly" on the scale, both for helpers and nonhelpers. Positive feelings (calm, proud, pleased with myself) ranged substantially higher. There were no significant differences due either to response or to experimental condition. Traces of any strong emotional disturbance were absent in these data.

Asked point blank whether the experiment should be permitted to continue, one person 
said no, but unfortunately he gave no reason. None said he regretted participating, although one expressed resentment at being deceived. The only negative response to an open-ended inquiry of whether "there was anything unethical in this experiment" criticized depriving people of the interesting discussion for which they had come; that is, the ethics of using a deceitful cover story were questioned, but the ethics of exposing people unwittingly to a threatening emergency were not mentioned. Finally, none believed this experience would reduce the likelihood of their helping a real victim in the future, whereas seven believed it would increase their helping.

Concerns about the ethics of a study cannot be allayed completely by participants' responses to anonymous ethics questionnaires. The ongoing feedback from the debriefings and from these questionnaires emboldened us, however, to continue the research to its conclusion.

\section{REFERENCE NOTES}

1. Beaman, A. L., Fraser, S. C., Diener, E., Kelem, R. T., \& Westford, K. The effects of evaluation apprehension and social comparison on emergency helping behavior. Unpublished manuscript, University of Montana, 1973.

2. Heberlein, T. A. Social norms and environmental quality. Paper presented at the meeting of the American Association for the Advancement of Science, New York, January 1975.

\section{REFERENCES}

Bickman, L. The effect of another bystander's ability to help on bystander intervention in an emergency. Journal of Experimental Social Psychology, 1971, 7, 367-379.

Bickman, L. Social influence and diffusion of responsibility in an emergency. Journal of Experimental Social Psychology, 1972, 8, 438-445.

Borofsky, G. L., Stollak, G. E., \& Messé, L. A. Sex differences in bystander reactions to physical assault. Journal of Experimental Social Psychology, 1971, 7, 313-318.

Clark, R. D., \& Word, L. E. Why don't bystanders help? Because of ambiguity? Journal of Personality and Social Psychology, 1972, 24, 392-400.

Clark, R. D., \& Word, L. E. Where is the apathetic bystander? Situational characteristics of the emergency. Journal of Personality and Social Psychology, 1974, 29, 279-288.

Darley, J. M., \& Latané, B. Bystander intervention in emergencies: Diffusion of responsibility. Journal of Personality and Social Psychology, 1968, 8, 377383.
Duval, S., \& Wicklund, R. A. A theory of objective self-awareness. New York: Academic Press, 1972.

Goodman, L. A. Simple methods for analyzing threefactor interaction in contingency tables. Journal of the American Statistical Association, 1964, 59, 319352 .

Horowitz, I. A. The effect of group norms on bystander intervention. Journal of Social Psychology, 1971, 83, 265-273.

Latané, B., \& Dabbs, J. M. Sex, group size and helping in three cities. Sociometry, 1975, 38, 180-194.

Latané, B., \& Darley, J. M. Group inhibition of bystander intervention. Journal of Personality and Social Psychology, 1968, 10, 215-221.

Latané, B., \& Darley, J. M. The unresponsive bystander-Why doesn't he help? New York: Appleton-Century-Crofts, 1970.

Latané, B., \& Darley, J. M. Help in a crisis: Bystander response to an emergency. Morristown, N.J.: General Learning Press, 1976.

Latané, B., \& Rodin, J. A lady in distress: Inhibiting effects of friends and strangers on bystander intervention. Journal of Experimental Social Psychology, 1969, 5, 189-202.

Moriarty, T. Crime, commitment and the responsive bystander: Two field experiments. Journal of Personality and Social Psychology, 1975, 31, 370-376.

Piliavin, I., Rodin, J., \& Piliavin, J. A. Good Samaritanism-An underground phenomenon? Journal of Personality and Social Psychology, 1969, 13, 289299.

Rosenthal, A. M. Thirty-eight witnesses. New York: McGraw-Hill, 1964.

Ross, A. S., \& Braband, J. Effect of increased responsibility on bystander intervention, II: The cue value of a blind person. Journal of Personality and Social Psychology, 1973, 25, 254-258.

Schwartz, S. H. Moral decision making and behavior. In J. Macaulay \& L. Berkowitz (Eds.), Altruism and helping behavior. New York: Academic Press, 1970.

Schwartz, S. H. Normative influences on altruism. In L. Berkowitz (Ed.), Advances in experimental social psychology (Vol. 10). New York: Academic Press, in press.

Schwartz, S. H., \& Clausen, G. T. Responsibility, norms, and helping in an emergency. Journal of Personality and Social Psychology, 1970, 16, 299310.

Smith, R. E., Smythe, L., \& Lien, D. Inhibition of helping behavior by a similar or dissimilar nonreactive fellow bystander. Journal of Personality and Social Psychology, 1972, 23, 414-419.

Smith, R. E., Vanderbilt, K., \& Callen, M. B. Social comparison and bystander intervention in emergencies. Journal of Applied Social Psychology, 1973, 3, 186-196.

Tilker, H. A. Socially responsible behavior as a function of observer responsibility and victim feedback. Journal of Personality and Social Psychology, 1970, 14, 95-100.

(Received March 20, 1976) 